\title{
Aptitude de l'espèce \\ Geotrichum candidum à la production \\ d'enzymes protéolytiques \\ NOTE COMPLEMENTAIRE
}

\author{
par \\ Micheline GUEGUEN et J. LENOIR \\ Laboratoire de Recherche de la Chaire de Technologie (I.N.R.A.) \\ Institut National Agronomique Paris-Grignon \\ 78850 Thivernal-Grignon
}

Dans une note antérieure* nous avons présenté les résultats des déterminations de l'aptitude à la production d'enzymes protéolytiques sur une collection de 30 souches de G. candidum. Pour l'essentiel, cette collection avait été constituée à partir de fromages de SaintNectaire d'origine fermière. Afin de disposer d'un échantillonnage plus large, de nouveaux isolements ont été effectués à partir de fromages de Pont-l'Evêque et de Camembert.

L'ensemble de la collection compte maintenant 83 souches de G. candidum et 4 souches de Geotrichum gracile. L'origine des souches de G. candidum est la suivante :

\begin{tabular}{c|c|c|c}
\hline Type de pâte & Type de fromage & $\begin{array}{c}\text { Origine de la } \\
\text { fabrication }\end{array}$ & Nombre de souches \\
\hline \multirow{2}{*}{ Pâte pressée } & $\begin{array}{c}\text { Tome de Savoie } \\
\text { Saint-Nectaire } \\
\text { Saint-Nectaire }\end{array}$ & $\begin{array}{c}\text { laitière } \\
\text { laitière } \\
\text { fermière }\end{array}$ & 1 \\
\hline Pâte molle & $\begin{array}{c}\text { Pont-l'Evêque } \\
\text { Pont-l'Evêque } \\
\text { Camembert }\end{array}$ & $\begin{array}{c}\text { laitière } \\
\text { fermière } \\
\text { laitière }\end{array}$ & 25 \\
\hline
\end{tabular}

* Micheline Gueguen et J. Lenotr, 1975. Le Lait, $n^{\circ}$ 543-544, 145-162. 


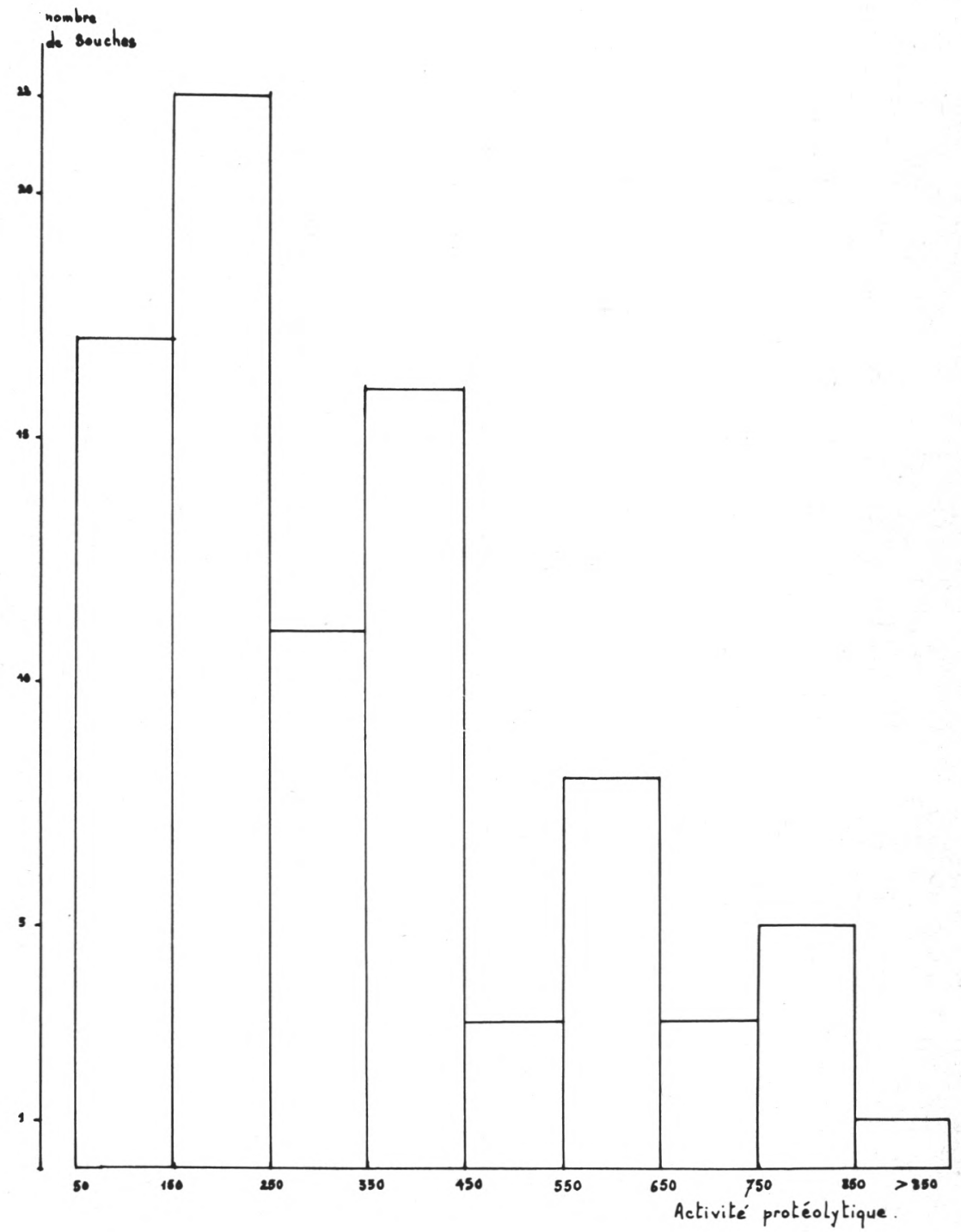

fig. 1

Distribution des souches de Geotrichum candidum de l'ensemble de la collection en fonction des activités protéolytiques extracellulaires. (Activités exprimées en $\mu \mathrm{g}$ de tyrosine / $\mathrm{ml}$ de milieu / h de digestion). 


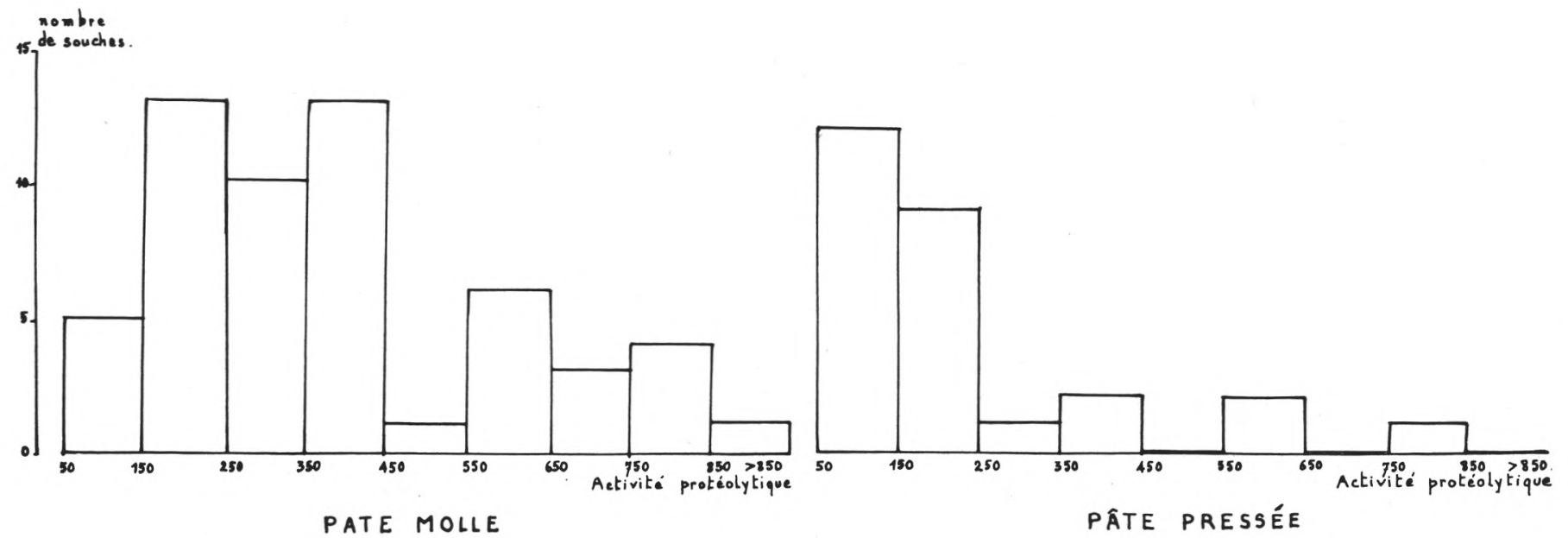

fig. 2

Distribution comparée des souches de Geotrichum candidum isolées à partir de fromages à pâte molle et à pâte pressée, en fonction des activités protéolytiques extracellulaires. (Activités exprimées en $\mu \mathrm{g}$ de tyrosine / ml de milieu / h de digestion). 
Les aptitudes à la croissance et à la production d'enzymes protéolytiques extracellulaires des souches, ont été éprouvées dans les conditions décrites antérieurement, à savoir : temps de culture de $11 \mathrm{j}$ à $23^{\circ} \mathrm{C}$ sur milieu Czapek-trypticase tamponné à $\mathrm{pH} 5,5$ à l'aide de tampon tris-maléate, digestion de $1 \mathrm{~h}$ à $\mathrm{pH} 6,0$ à $40^{\circ} \mathrm{C}$, en présence de substrat caséinate-citrate de sodium* et détermination des composés azotés solubles sur filtrat trichloracétique à la concentration finale de 2 p. 100 avec le réactif de Folin.

\section{*}

Les résultats obtenus dans cette deuxième série d'essais présentent certaines différences avec ceux de la première série, notamment en ce qui concerne la distribution des souches en fonction des poids de mycélium et des activités protéolytiques extracellulaires (fig. 1 et 2).

- Les souches produisant des poids de mycélium élevés, supérieurs à $0,45 \mathrm{~g}$ dominent, elles représentent les $3 / 4$ de la population.

- La proportion de souches présentant une forte activité protéolytique, supérieure à 350 , est sensiblement plus élevée, elle atteint près de la moitié de la population.

L'amplitude des variations observées dans les aptitudes à la croissance n'est pas modifiée par ces nouveaux résultats ; en revanche, celle de l'aptitude à la production d'enzymes se trouve légèrement accrue. En effet, dans cet essai, 7 souches se sont révélées plus fortement protéolytiques que les souches de la première série.

Par ailleurs, la corrélation entre la production d'enzymes et la croissance mycélienne, qui avait été précédemment relevée, se trouve assez nettement estompée après intégration des nouveaux résultats (fig. 3). Les coefficients de corrélation linéaire $(\mathrm{R})$, significatifs à 1 p. 100 , sont en effet : $+0,48$ pour les souches provenant des fromages à pâte molle, $+0,86$ pour celles isolées à partir des fromages à pâte pressée. Ces dernières peuvent, nous l'avons vu, être séparées en deux sous-groupes sur la base des aptitudes biochimiques et de l'aspect des cultures ; or on observe, pour le sous-groupe I, qui rassemble la plupart des souches (22), un coefficient $\mathrm{R}=+0,48$, c'est-àdire égal à celui qui caractérise la population isolée de fromages à pâte molle.

La relation entre la production d'enzymes et le $\mathrm{pH}$ du milieu en fin de culture n'est pas non plus très étroite. On peut, néanmoins, observer que, en règle générale, les souches qui ont une action alcalinisante, présentent une activité protéolytique plus élevée et une croissance mycélienne plus grande que les souches acidifiantes

\footnotetext{
* La présence de citrate dans le milieu de culture inhibe la production d'enzyme ; en revanche, elle n'a pas d'influence sur l'activité du système protéolytique.
} 


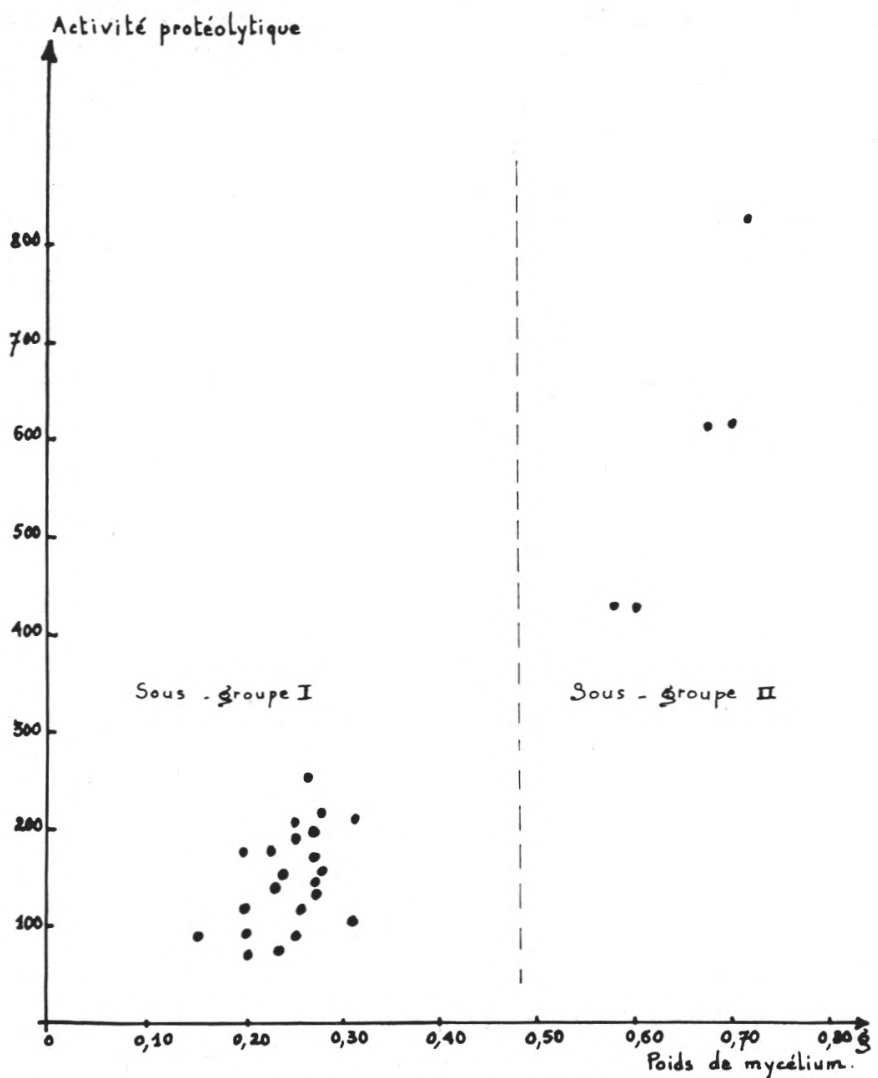

PATTE PRESSÉE

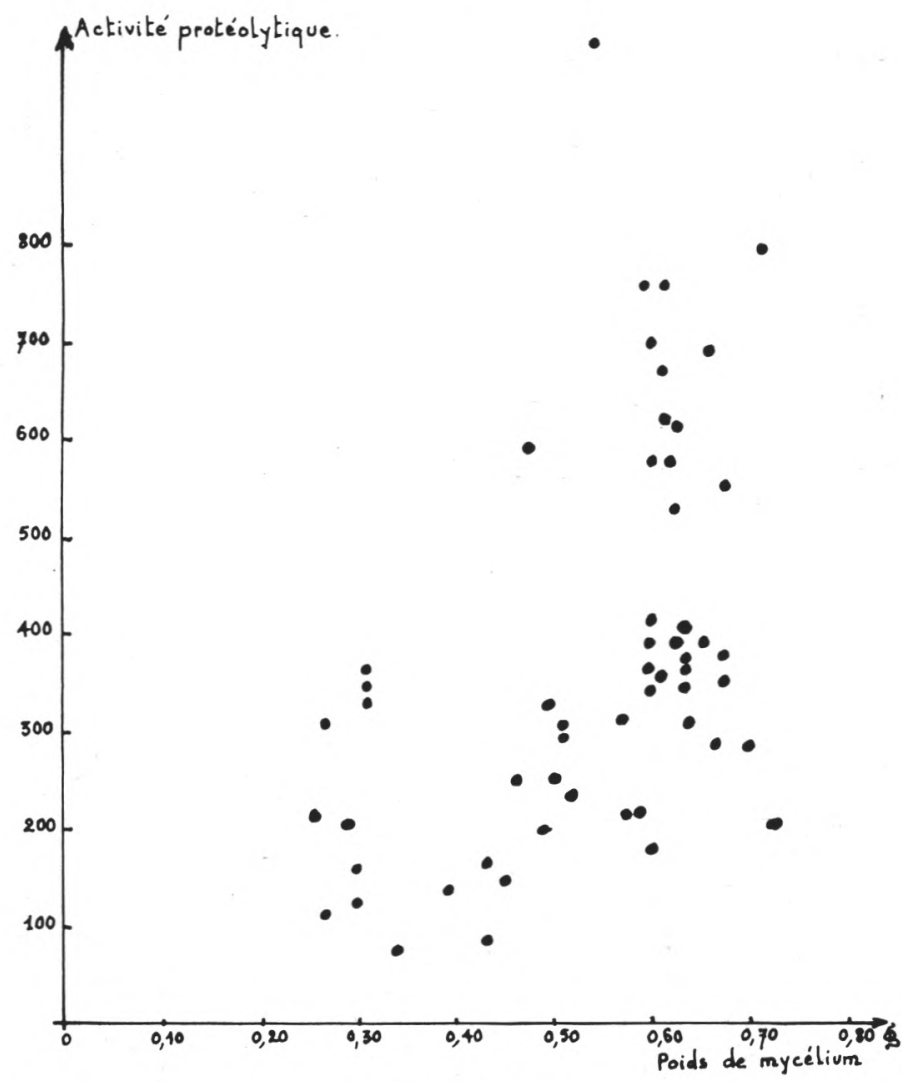

PATE MOLLE

Fig. 3 : Relation entre les activités protéolytiques extracellulaires et les poids de mycélium chez Geotrichum candidum Comparaison entre les souches isolées de fromages à pâte pressée et à pâte molle. 
(fig. 4 et 5). Il semble aussi qu'il y ait une relation entre le pouvoir alcalinisant ou acidifiant des souches et l'aspect des cultures. Les souches acidifiantes ont un aspect lévuriforme, elles forment une masse beige, visqueuse, en surface et au sein du milieu liquide, alors que les souches alcalinisantes ont plutôt l'aspect d'un mycélium vrai et elles se développent uniquement en surface sous forme d'un voile épais, irrégulier, légèrement duveteux.

Le classement des souches selon leur origine permet de faire aussi quelques observations.

La collection de souches isolées de Pont-l'Evêque comporte 29 souches provenant de fabrications fermières et 21 de fabrications laitières. Chez la presque totalité des souches d'origine fermière ( 86 p. 100), les activités ne dépassent pas 450 ; elles sont comprises, dans la plupart des cas, dans la zone $350-450$, mais les $3 / 4$ des souches ont des poids de mycélium compris entre 0,35 et 0,75 g.

Les souches provenant des fabrications laitières sont caractérisées par des poids de mycélium nettement plus élevés - les $3 / 4$ se situent dans l'intervalle 0,55-0,75 g - mais les activités protéolytiques sont beaucoup plus variables suivant les souches et la relation entre la croissance et l'activité est dans ce cas particulièrement lâche.

Si l'on compare les souches d'origines pâte pressée et pâte molle, on peut remarquer que, à quelques exceptions près, les G. candidum provenant de pâtes pressées sont caractérisés par des poids de mycélium faibles et des activités peu élevées ; alors que les souches isolées à partir de fromages à pâte molle ont, pour la plupart, une croissance plus active et une aptitude à la protéolyse plus marquée.

Le tableau ci-dessous résume les différences rencontrées suivant le type de pâte ; les valeurs des poids et des activités correspondent à 75 p. 100 des souches de l'un et l'autre types.

\begin{tabular}{c|c|c}
\hline Type de pâte & Poids de mycélium* & Activité protéolytique** $^{*}$ \\
\hline Pâte molle & $0,45-0,75$ & 50 à 450 \\
Pâte pressée & $0,15-0,35$ & 50 à 250 \\
\hline
\end{tabular}

* en g pour $40 \mathrm{ml}$ de milieu.

** en $\mu \mathrm{g}$ de tyrosine par $\mathrm{ml}$ de préparation enzymatique et par heure de digestion. 


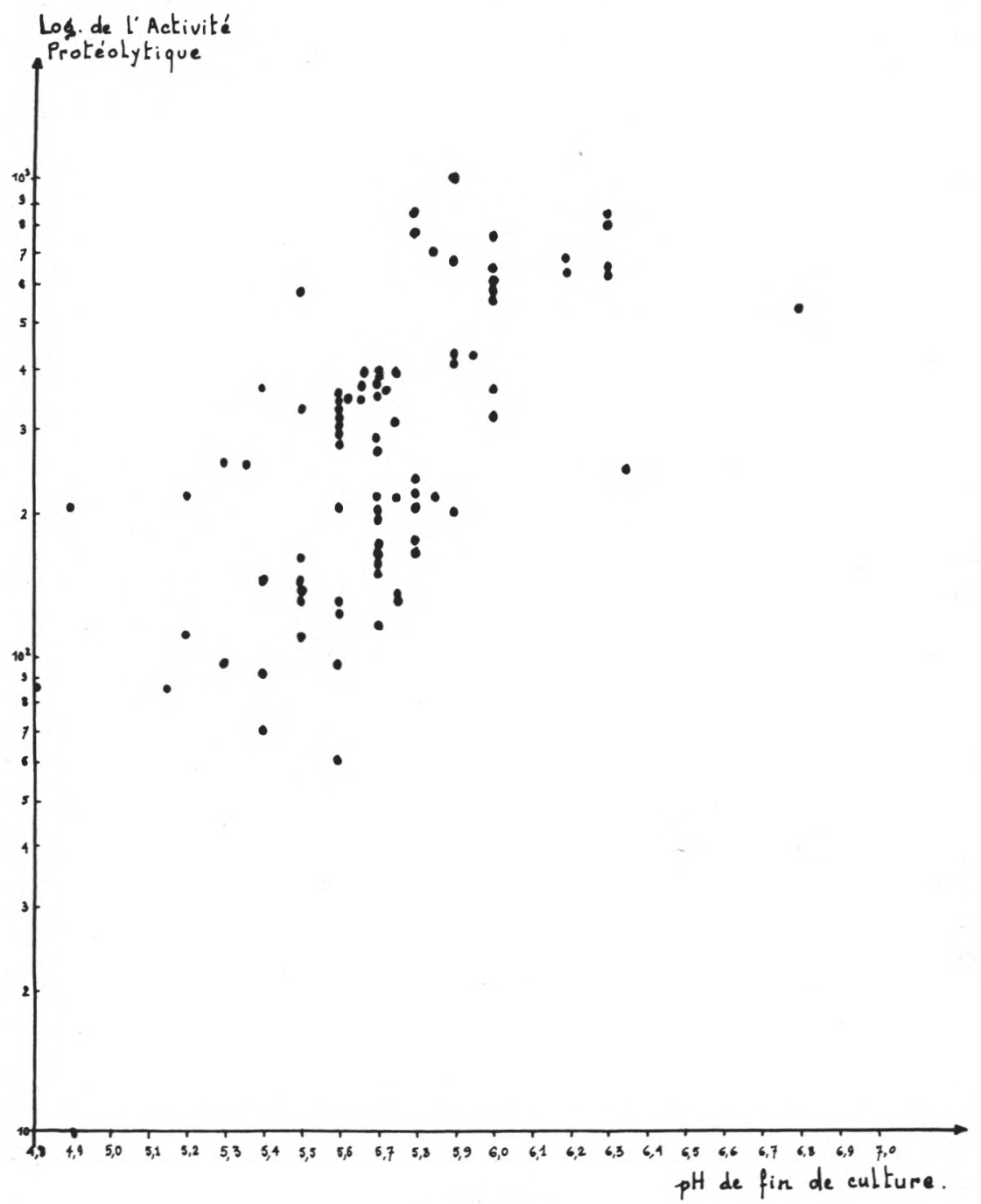

fig. 4

Relation entre les activités protéolytiques et les $\mathrm{pH}$ de fin de culture sur l'ensemble des souches de Geotrichum candidum.

\section{R és u mé}

L'aptitude à la protéolyse a été déterminée sur une collection de 83 souches de Geotrichum candidum et 4 souches de Geotrichum gracile, isolées pour l'essentiel de fromages de Saint-Nectaire et de Pont-l'Evêque. 


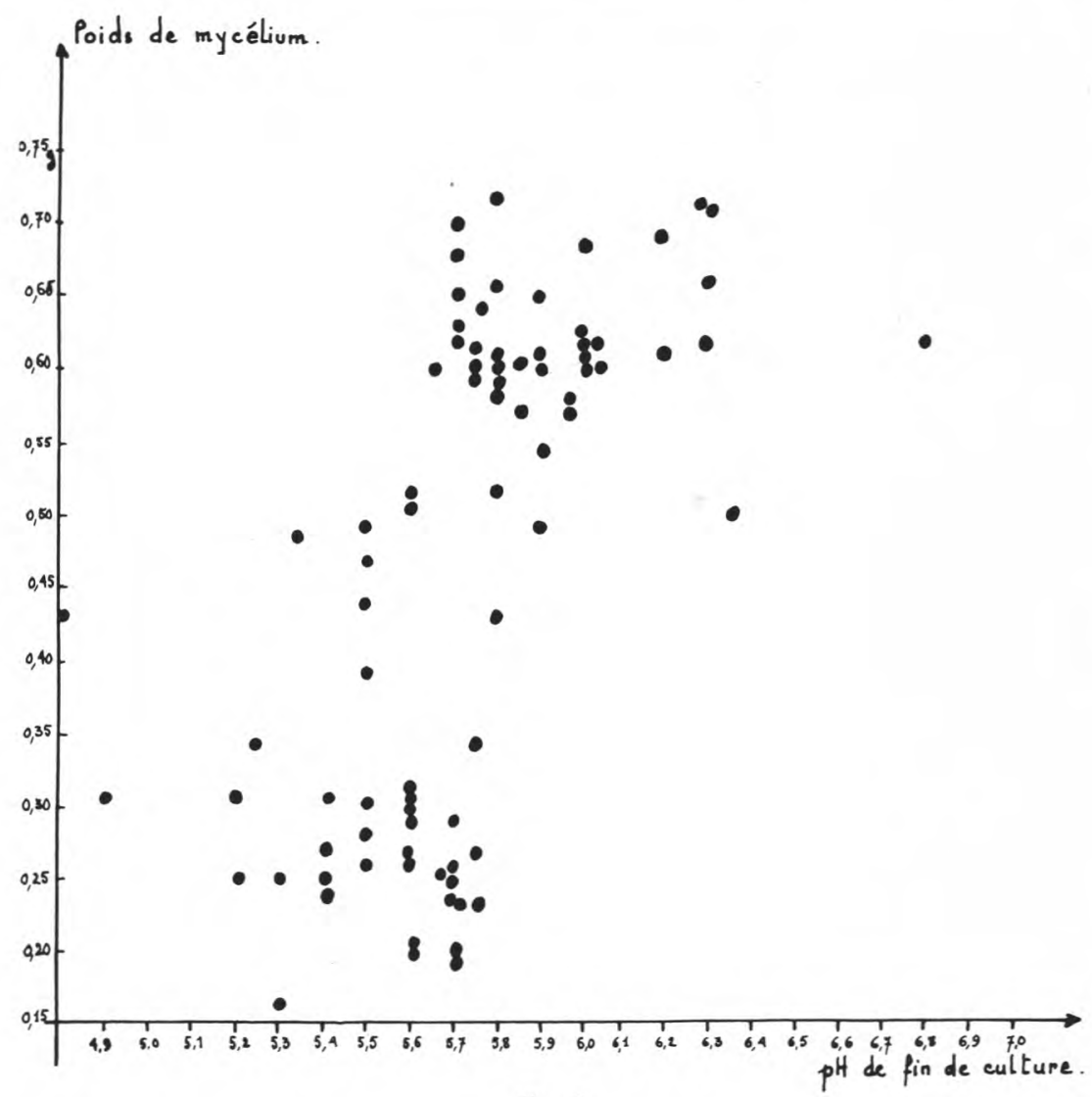

fig. 5

Relation entre les poids de mycélium et les $\mathrm{pH}$ de fin de culture sur l'ensemble des souches de Geotrichum candidum.

D'une souche à l'autre, les variations d'activité protéolytique présentent une assez grande amplitude. Les activités extra et intracellulaires varient dans un rapport de 1 à 15 ; 50 p. 100 des souches se situent dans les intervalles respectifs $150-450$ et $175-300 \mu \mathrm{g}$ tyr $/ \mathrm{ml} / \mathrm{h}$. Un classement des souches suivant leur origine a permis d'observer que celles isolées à partir des fromages à pâte molle ont, pour la plupart une croissance plus active et une aptitude à la protéolyse plus marquée que celles provenant des fromages à pâte pressée. Au sein de cette dernière population, l'existence de deux sous-groupes est mise en évidence. Ils se distinguent notamment par les caractères de culture, l'aptitude à la croissance et les activités protéolytiques extra et intracellulaires. Ces différences justifient une 
sélection des souches de G. candidum en vue de leur emploi en fromagerie.

\section{S u m m a r y}

A collection of 83 strains of Geotrichum candidum and 4 strains of Geotrichum gracile, most of which isolated from Saint-Nectaire and Pont-l'Evêque cheeses, has been made.

The amplitude of variation among the strains for the extra and intracellular proteolytic activities is about 1 to 15 , and these two activities are located respectively between 150 to 450 and 175 to $300 \mu \mathrm{g} \mathrm{tyr} / \mathrm{ml} / \mathrm{h}$. A classification of the strains according to their origin shows that most of those isolated from soft-cheeses have an increased growth and proteolytic activity than the ones from hardcheeses. In the latter population, two sub-groups are observed on the basis of cultural characteristics, growth-aptitude and extra and intracellular proteolytic activity. These differences justify a selection of the strains of $G$. candidum in the view of their use in cheesemaking. 